\title{
Identifying dangers in an uncertain climate
}

\author{
We need to research all the potential outcomes, not try to guess which is likeliest to occur.
}

Sir - Stephen Schneider, in his

Commentary "What is 'dangerous' climate

change?” (Nature 411, 17-19; 2001),

provides a succinct description of the

IPCC process and an excellent summary of the Special Report on Emissions Scenarios (SRES, of which we were among the lead authors), its findings and implications for climate change. He also gives a perceptive account of the critical issues that remain unresolved after completion of the comprehensive Third Assessment Report of the IPCC (see Schneider's Commentary for publication references).

Although we agree with most of what Schneider says, we disagree with him about the appropriateness and feasibility of assigning subjective probabilities of occurrence to alternative, unknown futures described by the SRES scenarios. In an interdisciplinary scientific assessment, the concept of probabilities as used in natural sciences should not be imposed on the social sciences. Probability in the natural sciences is a statistical approach relying on repeated experiments and frequencies of measured outcomes, in which the system to be analysed can be viewed as a 'black box'. Scenarios describing possible future developments in society, economy, technology, policy and so on, are radically different.

First, there are no independent observations and no repeated experiments: the future is unknown, and each future is 'path-dependent': that is, it results from a large series of conditionalities ('what if... then' assumptions) that need to be followed through in constructing internally consistent scenarios. Socioeconomic variables and their alternative future development paths cannot be combined at will and are not freely interchangeable because of their interdependencies. One should not, for example, create a scenario combining low fertility with high infant mortality, or zero economic growth with rapid technological change and productivity growth - since these do not tend to go together in real life any more than they do in demographic or economic theory.

Second, the 'what if... then' approach requires the explicit representation of a system to describe how the variables interact. That is, any randomly assumed distribution of 'what if' conditions (based on expert opinion about the future of world population, economic growth, technological development, diets and so on) would be insufficient without also assigning distributions to the conditional probabilities by which these assumed future states of driving forces interact to influence an unknown outcome (greenhouse-gas emissions). This means that the distributions of 'what if' as well as 'then' remain unknown.

We agree with Schneider about the dangers of arbitrarily picking a (too) limited set of scenarios. We also agree that it is important to be consistent in choosing which climate sensitivities to apply to which scenario. Resorting to a premature 'expert consensus' on the likelihood of certain emission futures and associated climate change in 100 years seems to ignore two essential facts: climate change has moved beyond the domain of 'experts' to that of a multitude of societal stakeholders; and good scientific arguments preclude determining 'probabilities' or the likelihood that future events will occur. The levels of future greenhouse-gas emissions and the ensuing climate change remain uncertain; we need adaptive response strategies that explicitly recognize these uncertainties.

So although we agree with Schneider in many respects, 'dangerous' levels of climate change will need to be identified by research into the adverse impacts on natural and human systems, independent of the question of how likely they are to occur, and covering the full range of scientific uncertainty.

There is a danger that Schneider's position might lead to a dismissal of uncertainty in favour of spuriously constructed 'expert' opinion.

Arnulf Grübler, Nebojsa Nakicenovic International Institute for Applied Systems Analysis, A-2361 Laxenburg, Austria

\section{Attention to bioweapons obscures the real threats}

Sir - Your News Feature "The bugs of war" (Nature 411, 232-235; 2001) brings lucidity to the debate about the threat of biological weapons. Until now, most assessments of this issue have been woefully inadequate in that they have dealt exclusively with political evaluations of possible technical vulnerabilities. Your News Feature gives an up-to-date depiction of the scientific reality behind the lopsided policy deliberations. We would like to add some points.

First is the issue of political motivation. If genetically engineered bioweapons were developed, would they be deployed by nation-states, terrorists or criminals? The problem is that as things stand there are more than enough non-engineered biological agents available to satisfy all these categories. Second, technical expertise is far too often overlooked. Even if a state or non-state actor has the wherewithal to manufacture an engineered bioweapon - which entails extensive technical expertise and a huge budget there remains the severe problem of adequate dispersal necessary for mass casualties. Bioweapons cannot be spoonfed to the intended targets. Delivery is an exceptionally difficult science, as has been found in state programmes (for example in the United States, the Soviet Union and Iraq) to create bioweapons. Finally, in any assessment it is important not to fall into the anthropocentric trap. The dangers of bioweapons directed at livestock and crops are as great as, if not greater than, those designed against people.

The conclusion of your News Feature, that whatever advances are made on the offensive side will have beneficial spin-offs on the defensive side, is important. Despite the overwhelmingly positive influence on society of the biomedical revolution, especially in genomics and proteomics, there are still problems, their potential misuse for weapons being just one. Knowledge does not automatically lead to capability. Your Opinion article in the same issue, "A call to arms" (Nature 411, 223 ; 2001) reminds us that, for terrorists, the gun and the bomb will continue to be the weapons of choice simply because these are more than adequate tools for political violence. As a result, we should be wary of being seduced by talk of a 'threat' of super-bioweapons. A balanced response by governments relies on accurate and proportionate risk assessments of the bioweapon threat. Without these, time and money will be wasted and, perhaps more important, the real threats will be overlooked.

Sebestyén Gorka ${ }^{\star}$, Richard Sullivan $\dagger$

${ }^{*}$ US Council for Emerging National Security Affairs, PO Box 378 Solebury, Pennsylvania 18963, USA

† Scientific Department, Cancer Research Campaign, 10 Cambridge Terrace,

London NW1 4JL, UK 